\title{
Correction: Towards responsible science and technology: How nanotechnology research and development is shaping risk governance practices in Australia
}

\author{
Yuwan Malakar (D), Justine Lacey (1) \& Paul M Bertsch
}

Correction to: Humanities and Social Sciences Communications https://doi.org/10.1057/s41599-021-01028-w, published online 11 January 2022.

The copyright holder for this article was incorrectly given as 'Crown' but should have been 'CSIRO'. The original article has been corrected.

Published online: 07 March 2022

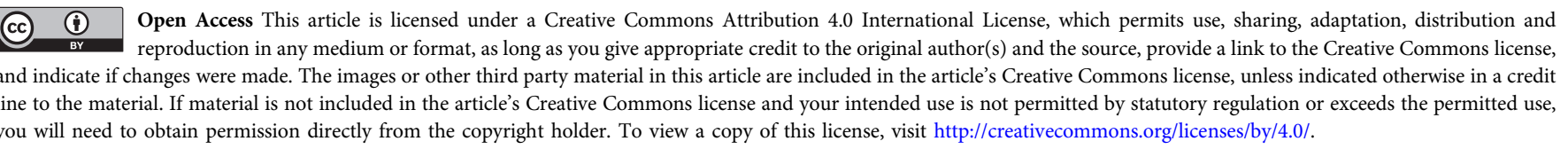

(c) CSIRO 2022 